\title{
Enfrentar el dolor ${ }^{1}$
}

\author{
Sandra Buechler ${ }^{2}$ \\ New York, USA
}

En esta extraordinaria reflexión y relato de vida, la autora revisa sus propias experiencias e interrogantes sobre cómo enfrentar el dolor humano, como el ser humano puede ser capaz, o no, y hasta que punto, de compartir el sufrimiento del otro.

Palabras clave: Dolor, Sufrimiento humano

In this extraordinary reflection and life story, the author reviews her own experiences and questions about how to face human pain, how the human being may or may not be able, and to what extent, to share the suffering of the other.

Key Words: Pain, Human suffering.

\section{English Title: Facing Pain}

\section{Cita bibliográfica / Reference citation:}

Buechler, S. (2020). Enfrentar el dolor. Clínica e Investigación Relacional, 14 (2): 330-348. [ISSN

1988-2939] [Recuperado de www.ceir.info] DOI: 10.21110/19882939.2020.140204

\footnotetext{
${ }^{1}$ Traducción castellana de Alejandro Ávila Espada.

2 Sandra Buechler, Ph.D. (New York), actualmente jubilada, ha sido Psicoanalista, Analista Didacta y Supervisora en el William Alanson White Institute y supervisora en el Programa postdoctoral y de Residentes del Columbia Presbyterian Hospital, asi como en el Institute for Contemporary Psychotherapy. Entre sus obras: Valores de la Clínica: Emociones que guían el tratamiento psicoanalítico (2004); Marcando la diferencia en las vidas de los pacientes: Experiencia emocional en el ámbito terapéutico (2008); Permanezco ejerciendo: Las alegrías y angustias de una carrera clínica (2012); Comprendiendo y tratando pacientes en Psicoanálisis Clínico: Lecciones desde la Literatura (2015); Reflexiones psicoanalíticas. Formación y práctica (2018) y La aproximación psicoanalítica a los problemas del vivir (2019).
} 
En la pintura de Peter Bruegel, "La caída de Icaro", vemos dos piernas frenéticas hundiéndose en un mar frío mientras todos los demás continúan con calma con sus tareas ordinarias. El gran poema de W.H. Auden,"Musee des Beaux Arts" declara que, al igual que otros maestros, Bruegel nunca se equivocó sobre el lugar que ocupa el sufrimiento. Uno de nosotros está cayendo en un abismo mientras los demás de nosotros continuamos con nuestras vidas. Las figuras de la pintura no son espectadores, ya que no parecen notar la caída. No es un evento para ellos, como sugiere Auden. Para Ícaro es el fin de su oportunidad de vida; para otros es un pequeño chapoteo poco importante. De hecho, mirando la pintura, me impresiona su quietud antinatural. El arado, los animales, el barco forman una especie de tableau, congelado en el tiempo. El momento esta encapsulado, como una escena nevada en una bola de cristal de Navidad, que usamos como pisapapeles. Por muy dispuesta o poco dispuesta, la conciencia está afectada o blasé, al mirar la escena en la que participo. Estoy en la frontera, encapsulada en mi propia quietud, mirando.

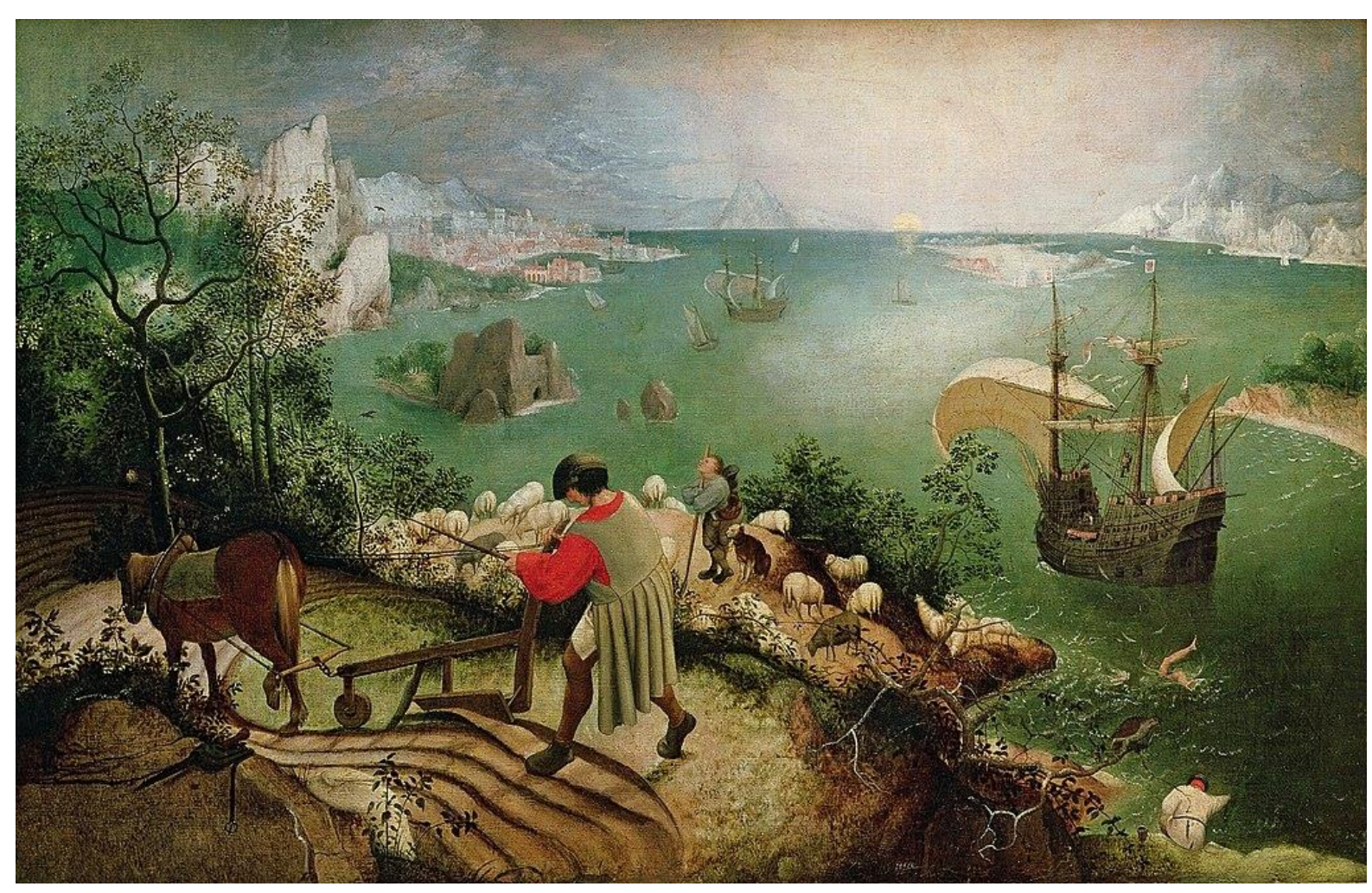

Creo que es el genio de Breugel lo que me invita a sentirme como un Ícaro desesperado al mismo tiempo que me identifico con el hombre que ara indiferente. Sé lo que se siente al hundirse, indefenso, ver la vida retroceder fuera de su alcance. Pero es igual de claro para mí 
que sé lo que es ser indiferente a las tragedias en el siguiente cuadro, fuera de la vista, fuera de la mente. Debido a que está sucediendo allí, es fácil dejar que siga siendo irreal. Al pintarlo como un tableau, Bruegel me ha invitado a habitar una burbuja separada, como el arado y el caballo, para conocerme a mí misma como ellos, tal como también me conozco a mí misma como Ícaro. Ni siquiera tengo que apartarme de él, porque nunca me he vuelto hacia él. No soy consciente de que evito. Estoy en una zona diferente, donde no hay piernas golpeando irremediablemente el agua fría, inflexible, una última vez. En un momento una caída gradual se convertirá en una ausencia permanente, un esfuerzo inútil cediendo a medida que las piernas se hunden en la muerte.

Acostumbrarme a la idea de la guerra me parece la mayor hazaña de desprecio. Todos sabemos lo que hace la guerra, cómo destroza a la gente. Hemos visto las pinturas "negras" de Goya ("Desastres de la Guerra"). En una imagen inolvidable ("Duelo a Garrotazos") retrata a dos hombres que luchan entre sí arrastrándose uno al otro en arenas movedizas, en lugar de salvarse uno a otro y a sí mismos. El "Guernica" de Picasso narra un momento y un lugar particulares, pero es la historia interminable propia, y en cualquier otro momento de la historia. ¿Cuál es el proceso por el cual llegamos a ser capaces de vivir con este conocimiento? ¿Requiere que sepamos y, al mismo tiempo, no sepamos completamente de los que están siendo masacrados hoy? ¿Enseñamos a nuestros hijos este proceso o lo vienen por sí solos? ¿Todos aprendemos las mismas tácticas? ¿Algunos de nosotros estamos naturalmente bien aislados? ¿Están ellos mejor?

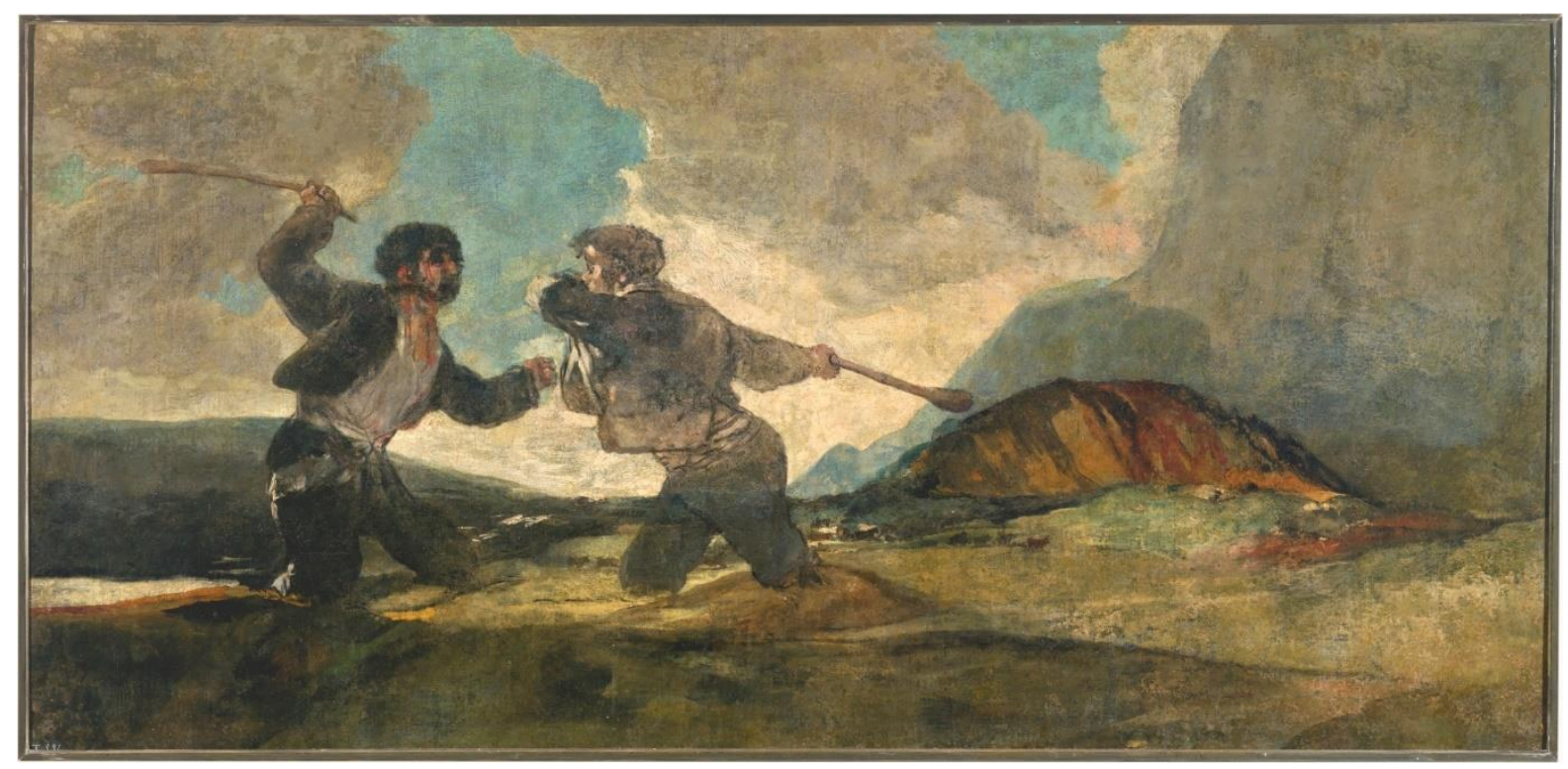

(c) Derechos reservados/Copyright de Clínica e investigación Relacional y los autores. Prohibida la reproducción total o parcial sin autorización expresa. Este material es para uso científico y profesional exclusivamente y puede contener información clínica sensible. Los editores no se responsabilizan de los contenidos de los autores. Dirigir las consultas sobre derechos y autorizaciones a ceir@psicoterapiarelacional.es 
Vivir en las cercanías de la tragedia no es nuevo para mí. En mis veinte años, con muy poca preparación profesional y personal, trabajé como psicóloga en un hospital psiquiátrico del estado de Nueva York, en un pabellón con pacientes psicóticos crónicos, y en dos hospitales de veteranos de guerra, con pacientes varones agudos y crónicos. La mayor parte del tiempo, luché con las náuseas. No conseguimos encontrar su ubicación exacta. La mayoría de los pacientes miraban fijamente, con los ojos vidriosos, an la televisión en la gran sala de día. Sus dedos estaban amarillentos por las colillas de los cigarrillos. No sé cómo, pero aprendí a no parecer sorprendida, pasase lo que pasase. $Y$ cualquier cosa podría pasar en cualquier momento. Los pacientes exponían partes del cuerpo, defecaban, perforaban el aire con gritos de agonía, suplicaban ser liberados, o simplemente pedían ser escuchados, tal como contaban su historia incoherente, pero con aflicción sincera.

Me di lo que yo llamaba mis "órdenes de ponerme en marcha". Sólo hazlo. El tiempo pasaba lentamente. No quería parecer conmovida, porque eso mostraría lo poco preparada que estaba. Tuve que "hacerlo", lo que significaba pasar por alguien que sabía que no era. Los trabajadores sociales, los psiquiatras, las enfermeras y ayudantes, todos parecían ser capaces de respirar, y, a veces, incluso de sonreír o bromear. Ninguno de ellos parecía estar como yo me sentía.

Aparte de los problemas de carácter y la historia personal que traje a la situación, tuve el hándicap de parecer aún más joven de lo que era. Me imaginé que los responsables del hospital estaban pensando que no estaba capacitada en mi trabajo. Eso es ciertamente lo que estaba pensando. Pero debido a esto, sentí aún más presión para no parecer desconcertada. Como si no oyera los gritos, o fueran ruidos sin sentido que podía ignorar, no seres humanos con dolor.

Una de mis luchas internas fue qué mirar cuando entré en el pabellón psiquiátrico. ¿Debo mirar a la cara de la paciente gritando, sollozando o, más discretamente, mirar más allá de ella? Si no miro fijamente, ¿estoy siendo considerada, compasiva o cobarde? En presencia del extraño que sufre, ¿cómo nos conectamos sin entrometernos? Pero tan pronto como me pregunto esto, recuerdo el punto de vista perfectamente viable (Severson, 2011) de que mi motivo no importa en lo más mínimo. El sufrimiento es lo único que importa.

(Sontag, 2003, p. 37) "...hay vergüenza, así como shock al mirar el primer plano de un verdadero horror... (pág. 38)"... lo espantoso nos invita a ser espectadores o cobardes, incapaces de mirar.

Tal como lo he experimentado, el vínculo en presencia del dolor puro y duro en otro ser humano es que puede sentirse mal el mirar y también mal mirar hacia otro lado. Mirando se siente como elegir que destacar, que exponer. Me somete a la vergüenza y a la culpa de ser un 
voyeur. Al mirar subrayo implícitamente la diferencia entre nosotros, o eso puede parecer. Pero mirar hacia otro lado puede decir al enfermo "estás más allá de la palidez. Obsceno. Digno sólo de desprecio". Es como si el sufrimiento fuera una escena primaria. Mirar puede ser sentido como que estoy agravando la miseria de la otra persona con una capa añadida, innecesaria, de humillación.

Sontag (2009, pp. 85-88) menciona a varios filósofos que han analizado los motivos menos nobles detrás de nuestra fascinación por las imágenes del sufrimiento humano. Cita a Edmund Burke, quien creía que la gente se deleitaba con el dolor de los demás. Georges Bataille mantuvo una foto de un prisionero sometido a tortura en su escritorio, y comentó que la foto ha jugado un papel decisivo en su vida. Se declaró obsesionado por ello, y teorizó que la imagen servía para adormecerlo frente al dolor, entre otras funciones. Sontag menciona otro señuelo- el consuelo de que no me está sucediendo.

Pero mi propio impulso es mirar hacia otro lado, que, al menos para mí, puede sentirse igualmente perverso. Porque no estoy segura de poder soportar mirar, mirar hacia otro lado parece egoísta y débil. Creo que esta conexión acerca de mirar a la cara del enfermo no es simplemente un problema en el plano visual. Creo que el conflicto sobre la búsqueda se juega en niveles menos concretos. El ojo de mi mente tiene que ver con sobre qué enfocarme y sobre qué no enfocarme. Esto afecta a cuanto estoy dispuesta / soy capaz de contemplar lo que los solicitantes de asilo desesperados están experimentando todos los días. ¿Puedo permitirme imaginar las agonizantes decisiones que están tomando los padres, en este momento, sobre si arriesgar un viaje peligroso con la esperanza de que a ellos y a sus hijos se les permita intentar tener una vida mejor en este país? En mi mente, en mi corazón, ¿puedo "mirar" a los niños en jaulas, separados de sus padres, cuyo único "crimen" es la decisión de sus padres de embarcarse en un viaje desesperado? Mi proceso de pensamiento no les importa en realidad, pero el hábito de la evasión visual se generaliza a mi mente, de modo que, sin tomar una decisión consciente, no registro el chapoteo del agua como el Ícaro de hoy que paga con su vida por sus altas esperanzas.

Hay una situación que me deja libre para mirar a los que están desgastados por la miseria y doblegados por el envejecimiento; cuando veo sus caras en las paredes de los museos. Hablando solo por mí, puedo decir que encuentro esto liberador. Me encuentro con el despiadado autorretrato de Rembrandt en 1660 a los 54 años, con su piel enrojecida, arrugada y curtida, cabello abundante, cejas fruncidas y papada, y puedo mirar todo lo que quiera, sin temor a ofenderlo o lastimarlo. Como Winnicott describió tan brillantemente en su concepto de cultura como espacio de transición, me tomo el descanso de diferenciar lo que viene de dentro de mí y lo que viene de la realidad externa. Me imagino que se encuentra con mi mirada 
su propia mirada desafiante e inquebrantable. Fantaseo con que está diciendo: "Adelante. Mira todo lo que quieras. Juzga cómo he dejado que la vida me altere. No me importa. No necesito cubrirme ni arreglarme. Puedo mostrarme exactamente como soy". No tengo ni idea de si estos pensamientos también eran de Rembrandt o provienen enteramente de mí. Y no importa.

Recuerdo la declaración de T.S. Eliot de que "los viejos deberían ser exploradores..." Rembrandt ciertamente asumió este desafío, exploró las manifestaciones de su mundo interior y trazó sus descubrimientos en los autorretratos. Sé que, en realidad, a medida que envejecía, fue cada vez más criticado por su estilo "duro" y su falta de voluntad para idealizar sus temas. Me imagino que siente que llegar a la verdad era más importante que cualquier otra cosa. Mi fantasía más optimista es que la satisfacción lo compensó ( $y$, tal vez, puede compensarme) por todas las pérdidas. Sabemos que Rembrandt sufrió terribles pérdidas, su esposa, todos sus hijos, cayó en bancarrota, su casa, la mayoría de sus posesiones, por no hablar del precio ordinario y exacto del envejecimiento. Y sin embargo, continuó pintando. Estos son hechos que mis imaginaciones sobre lo que podría haberlo sostenido. ¿Por qué dedica tanto esfuerzo artístico a retratar a profetas ancianos, mártires que sufren, duelos afligidos y tantos otros pasajes dolorosos? ¿Podría ser que todos tengamos que mirar, sin conflictos, sin miedo, el sufrimiento que ha sido, y/o será, algún día, nuestro?

Un anciano se tiende en la acera, cerca de mi edificio de apartamentos. Con una voz sin expresión menciona que le gustaría dinero para la comida. Su tono está totalmente desprovisto de cualquier clase de sentimiento. Sin ira, sin deseo. No suplica. Su secuencia de palabras (dinero para la comida) es dicha como una declaración plana, sin flexiones. Cerca, una mujer, sosteniendo un bebé, hace una petición más clara, con dolor, con una súplica. ¿Quién soy si miro hacia otro lado y quién soy si miro? ¿Hasta dónde debo (puedo) llegar para verlos realmente $y$, por mucho que vaya, ¿para quién es realmente? Ignorarlos se siente monstruoso. Pero el desigual desfile es interminable.

El periódico de hoy (New York Times Magazine, Domingo, 3 de noviembre de 2019, "The Haunted", págs. 32 a 43, por Jennifer Perry) describe a niños torturados durante años por el Estado islámico (ISIS), y hombres y mujeres violados, vendidos, asesinados. Un niño de doce años, cautivo durante cinco años, hambriento, con el cuerpo cubierto de cicatrices. Una chica que había sido capturada por el ISIS a los 4 años y ahora tenía 9 años, sangrando por todas partes, con la frente marcada al ser golpeada todos los días con una barra de metal. Una mujer cuenta que un miembro del ISIS puso a su hija de dos años en una caja de hojalata y lo dejó al sol, y luego, frente a la madre, rompió la espalda de la bebé golpeándola en el suelo. Le dijo a la madre que así es como todos los incrédulos tienen que morir. Otro combatiente del ISIS 
explica que los yazidies tienen que morir porque no son humanos. ¿Qué es un humano, o incluso una respuesta sensata a este catálogo de horrores? Me imagino lo que estoy leyendo hasta que ya no puedo. Sin que yo sea consciente de ello, creo que al leer esto, mi mirada y mis pensamientos se desvían del hombre de carne y hueso tendido en mi acera, que habla monótonamente de dinero para comida. La lectura ha agotado la cuota de compasión de mi día.

Recuerdo la conmovedora escena, en "Rey Lear", cuando la compasión por el "mendigo" (realmente Edgar disfrazado) penetra en el alma de Lear, y lamenta profundamente su desprecio previo de la difícil situación de aquellos que se enfrentan a los elementos desprotegidos.

Pobres miserables desnudos, estés donde estés,

Que aguantan el azote de esta despiadada tormenta

¿Cómo serán tus cabezas sin hogar y tus lados sin alimento,

Tu andrajosidad en bucle y ventana, te defiende

¿De temporadas como estas? ¡Oh! He tomado

Muy poco cuidado de esto. Toma medicina, Pomp;

Exponte a sentir lo que sienten los miserables,

Para que les sacudas el superflujo,

Y mostrar los cielos más justos.

(Acto III, escena 4, líneas 27-36)

(Arden Shakespeare, p.108)

Supongo que "exponerse" es suficiente para permitirse sentir el sufrimiento de los demás si el descuido anterior no fue deliberado. Pero, para mí, esto plantea una cuestión muy complicada. Cuando no parezco oír el chapoteo de Ícaro estoy eligiendo ser impermeable (¿tal vez inconscientemente?) Alain de Botton y John Armstrong ("Arte como Terapia" 2013, Phaidon Press, N.Y., p.141) señalan el muy obvio, pero sin embargo interesante, punto de que nos percibimos desde dentro, pero percibimos a los demás desde el exterior. "Una característica central de la experiencia humana es que, si bien nos conocemos desde dentro, y tenemos una comprensión inmediata e intuitiva de lo que es ser nosotros mismos, nos encontramos con otros sólo externamente. Podemos sentirnos cerca, podemos llegar a conocerlos bien, pero queda un vacío". En otra parte (2008) he escrito sobre la inevitabilidad de que el dolor que siento hoy está moldeado por toda mi historia de dolor y, por lo tanto, es, 
a diferencia de cualquier otra persona y, en última instancia, incognoscible por nadie más. La gente puede decir, "Siento tu dolor" pero nadie realmente lo hace. Podemos sentir algo que se aproxima, pero sólo podemos sentir nuestro propio dolor, moldeado por todo el sufrimiento que lo precedió en nuestras vidas.

Esto me ayuda a entender por qué algunos sufrimientos van acompañados de una extrema sensación de aislamiento. No importa lo amables y empáticos que sean los demás, hay un núcleo duro de mi sufrimiento que nadie más entiende. Recuerdo la obra de Helene Deutsch ("Confrontaciones conmigo misma", Nueva York: W.W. Norton, 1973) una autobiografía, donde ve la soledad como un producto de saber que eres el único que ve las cosas como tú. Es decir, significa que las personas pueden pensar erróneamente que, porque pueden reconocer la superficie_del dolor de alguien, porque parece un sentimiento familiar para ellos, lo entienden. Lo que no captan es que el dolor que siento hoy reverbera, recogiendo ecos de experiencias pasadas. La mayor parte del tiempo no tengo palabras para este acompañamiento, así que incluso yo mismo, puede que no me dé cuenta de por qué me siento como yo. Cuando otra persona, tal vez por el deseo de consolarme, responde a lo que parezco que estoy experimentando, invariablemente se pierde. Para mí esto confirma la amplitud de la brecha entre nosotros. Su intento de ser compasivo solo aumentó mi soledad. Y ahora, a esta carga, se suma el sentimiento de que debo estar agradecido por su solicitud.

Tales fracasos empáticos bien intencionados no son infrecuentes en el tratamiento. Por lo general, es el analista en el papel de ayudante potencial. A veces, como analista, me ha intrigado la razón por la que mi empatía no está teniendo el efecto deseado. Puede ser fácil culpar al paciente por estar inconsolable. Estas interacciones pueden ser muy difíciles de desentrañar. Creo que la mayoría de las veces ninguno de los participantes las expresa, ni las entiende en absoluto.

Pero como analista, a veces he sido objeto de los esfuerzos mal sintonizados de la otra persona por consolarme. De alguna manera, en esa situación, la ingratitud de mi parte ha parecido

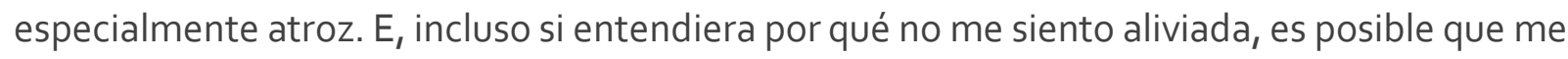
resista a explicar qué es lo que "va mal". Me viene a la mente el ejemplo del fallido "análisis mutuo" de Ferenczi. Una vez que empiezo a recorrer el camino de la historia de mi propio sufrimiento, ¿dónde termina?.

Últimamente, creo que se está prestando más atención al "sanador herido". El trabajo de Donna Orange $(2011,2016)$ es especialmente pertinente. He escrito en otro lugar sobre la soledad, el dolor, la vergüenza, la culpa y otros sentimientos muy dolorosos que he experimentado en el curso de mi práctica clínica. No lo repetiré todo, excepto para decir que, si bien la tendencia actual es compartir esta "contratransferencia" con el paciente, e incluso 
en 1949, Winnicott advirtió a los terapeutas que un tratamiento no se terminaba hasta que se expresaba el "odio" almacenado por el clínico. Para el paciente, sin embargo, puede ser extremadamente difícil juzgar cuándo, cómo y qué compartir. Pero, en cualquier caso, en mi experiencia, el clínico está solo con el enigma en sí. Esto ha reforzado el peculiar aislamiento de su papel. Cuando hacemos trabajo clínico, nunca estamos solos, pero eso no significa que no estemos solos.

A veces he denominado "crueldad necesaria" a un requisito para hacer un tratamiento. Lo que quiero decir con eso es que a veces los clínicos no podemos permitirnos ser silenciados por el miedo a la posible reacción del paciente. En un cóctel, si sentimos que estamos diciendo algo que podría incomodar a la otra persona, es probable que cambiemos de tema o quedemos en silencio. Pero hacer el tratamiento tiene un conjunto diferente de prioridades, que a menudo incluyen enfrentar las defensas, persuadidos de que el material está plagado de conflictos que no son conscientes e, implícitamente, implica que la verdad puede hacernos libres. Llamar "crueldad" a la luz verde que nos damos a nosotros mismos puede ser una exageración, pero es la única forma que he encontrado para describir lo que quiero decir. Sin embargo, en mi experiencia, ser despiadado puede provocar (nuestro) aislamiento, especialmente porque a menudo es el resultado de un juicio cercano. Así como mirar fijamente a la cara de un otro que sufre puede parecer tanto correcto como incorrecto, sacar la verdad dolorosa de su escondite puede resultar igualmente ambiguo desde el punto de vista moral. A veces he bromeado sobre que la escuela primaria es la última vez que podemos elegir entre el bien y el mal, ya que la mayor parte del resto de la vida nos enfrenta a elecciones entre mal y más mal, o bien y más correcto. A menudo he sentido un tipo particular de soledad en esta posición. No es solo que no pueda compartir lo que siento con nadie más (al menos en ese momento, si no para siempre). Es que ni siquiera me tengo conmigo. Es decir, puede que no sienta el tipo de convicción sobre lo que estoy haciendo que pueda mitigar mi aislamiento.

En un poema encantador y característicamente autocrítico, (Helen Vendler, "Dickinson: Poemas escogidos y comentarios, Harvard University Press, 2010, Cambridge,"Poema 550", págs. 250-254), Emily Dickinson intenta "medir" su dolor contra los dolores que intuye que los demás sienten. En su mente, "ve" un desfile de dolientes y adivina sobre las fuentes de su sufrimiento. Reconoce que puede no etiquetar correctamente sus dolores, aunque le gustaría poder presumir que algunos son como los suyos". Con su genio para la introspección, Dickinson nombra el deseo de borrar la frontera entre el yo y el otro, para sentirse un poco menos solo con las inevitables cargas de la vida.

Ese límite entre uno mismo y el que sufre a veces puede ser un obstáculo para la conexión, pero también puede ser vital, tal vez, incluso, para salvar vidas. Rilke, en "Los cuadernos de 
Malte Laurids Brigge" (W Norton and Co., 1964, traducido por M.D. Herter Norton, NY) tiene mucho que decir sobre las agonías del protagonista en respuesta al sufrimiento que percibe en los demás. A veces parece como si Brigge se sintiera invadido por el dolor del mundo, sin fronteras que lo protegieran. Aunque Rilke afirma que este personaje es ficticio, es ampliamente reconocido (sugiere el traductor) hacer eco de las declaraciones de Rilke sobre su propia vida. Brigge experimenta (p.68) "iLa existencia de lo horrible en cada partícula de aire! Lo inhalas con lo que es transparente; pero dentro de ti se precipita, se endurece, toma formas puntiagudas y geométricas entre tus órganos; para cualquier tormento y el horror ha sucedido en los lugares de ejecución, en las cámaras de tortura, manicomios, quirófanos, bajo las bóvedas de los puentes a finales de otoño: todo esto tiene una áspera impermeabilidad, todo esto subsiste por derecho propio y, celoso de todo lo que es, se aferra a su propia realidad espantosa. A la gente le gustaría que se le permitiera olvidar gran parte de esto, el sueño vuela suavemente sobre esos surcos en sus cerebros, pero los sueños ahuyentan al sueño y vuelven a trazar los diseños".

En su fascinante biografía de la relación entre Rilke y Rodin, Rachel Corbett ("Debes cambiar tu vida", W.W. Norton, 2016, p. 99) analiza el método de Rilke para entrar en el otro, al que llamó "inseeing" (Viendo hacia dentro). Inseeing describió el maravilloso viaje desde la superficie de una cosa hasta su corazón, en el que la percepción conduce a una conexión emocional... Si se enfrenta a una roca, por ejemplo, uno debe mirar profundamente en el lugar donde comienza a formarse su roca. El observador debe seguir mirando hasta que su propio centro comience a hundirse con el peso de piedra de la roca que se forma dentro de él también. Es un tipo de percepción que tiene lugar dentro del cuerpo, y requiere que el observador sea tanto el vidente como lo visto. Para observar con empatía, se ve no sólo con los ojos sino con la piel".

Dada la pobreza, la enfermedad y la "existencia de lo horrible en cada partícula de aire" alrededor de Rilke, podemos imaginar que "sentir" podría resultar tremendamente doloroso, a veces, creando eventualmente una profunda necesidad de alguna forma de defensa. ¡Seguramente cualquiera que se inclinara a fusionarse con tal tormento eventualmente tendría que aprender a crear un espacio personal separado, menos asfixiante, con bordes firmes!

Y, de hecho, leemos en el relato de Corbett que Rilke encontró una manera de hacer precisamente eso, al principio hundiéndose y celebrando la separación, incluso de su esposa e hijo. (p.162) "De nuevo he acumulado tanto anhelo de la completa soledad" ... "Ahora no era hijo de nadie, secretario de nadie. Ya casi ni siquiera era padre o esposo ..." Pero ni siquiera el aislamiento lo hacía. Para protegerlo lo suficiente, ya que el sufrimiento humano estaba en el 
mismo aire que respiraba y no podía vivir completamente solo, tuvo que desarrollar mecanismos de afrontamiento menos drásticos. Corbett (p. 218) describe a Rilke teniendo que aprender a manejar la intrusión en la vida de otras personas. Con su desarrollo del "sentir", vino la necesidad y, eventualmente, la capacidad de revertir el proceso y defenderse de ser engullido. "En el pasado, ir al Louvre había significado prepararse para una embestida de carne y rostros, lo real a menudo indistinguible de los que estaban en el lienzo. Pero ahora aprendió a detenerse antes de que sus sentidos lo abrumaran, cerrar los ojos e imaginar la fortaleza los bordes de su cuerpo, como si fueran muros de un castillo ". En sus propias palabras (citado por Corbett, p. 218) "(Yo) estiré mis contornos, como uno estira las cuerdas de un violín, hasta que uno las siente tensas y cantando, y de repente supe que estaba completamente perfilado como un dibujo de Durero".

¿Qué sucede si un niño muy sensible se sobresalta por su propio "sentir" y pierde la distinción entre sí mismo y sufriente? En un poema que siempre he encontrado asombrosa, Elizabeth Bishop describe una experiencia así, presumiblemente de su propia infancia. Este poema tiene la asombrosa habilidad de pintar un cuadro extremadamente claro, pero permanece, al menos para mí, lleno de fascinantes misterios. En el poema, ("Un despertar" en Seiden, págs. 22-27), la pequeña Elizabeth, apenas antes de su séptimo cumpleaños, se sienta en la sala de espera mientras su tía es tratada por el dentista. Al escuchar el repentino grito de dolor de su tía, Elizabeth no se sorprendió, porque ya consideraba a su tía como tonta y tímida. Pero algo más fue un shock.

Sin pensar en nada

Yo fui mi tía tonta,

Caímos, caímos ...

Yo sabía que nada extraño

había pasado alguna vez, que nada

algo extraño podría suceder.

¿Por qué debería ser mi tía?

¿O yo, o alguien?

Aquí la pérdida de la distinción entre uno mismo y el que sufre se produce de forma espontánea. Elizabeth ha sido sacada de la vida ordinaria hacia un territorio resbaladizo, donde se siente caer y caer $y$, tal vez, nunca volver a aterrizar en tierra firme. La vida puede parecer tan arbitraria y, a veces, tan injusta. ¿Por qué un Ícaro se sale con la suya volando alto, mientras que otro se precipita? ¿Por qué un niño contrae leucemia, una casa se derrumba en expresa. Este material es para uso científico y profesional exclusivamente y puede contener información clínica sensible. Los editores no se responsabilizan de los contenidos de los autores. Dirigir las consultas sobre derechos y autorizaciones a ceir@psicoterapiarelacional.es 
un terremoto, mientras que las casas vecinas permanecen intactas? De repente, sorprendidos por lo absurdo de la vida, podemos desatarnos y preguntarnos por qué habitamos una piel en particular. Pero lo que es tan desconcertante y absorbente para mí es que realmente no tengo idea de cuánto se parece mi línea de pensamiento al dilema de Elizabeth. En otras palabras, no estoy seguro de dónde termina Elizabeth y comienzo yo, pero me siento profundamente atraído por tratar de resolverlo. Bishop y yo me puse en el lugar de la pequeña Elizabeth.

Pero, aunque gravito hacia estos desafíos, también desconfío de ellos. Las incursiones fuera de mí pueden comenzar a sentirse demasiado permanentes. Recuerdo una vez, al final de un largo viaje, cuando, en un sentido literalmente desagradable, viajar comenzaba a sentirse como un deambular errático. ¿Cuánto tiempo puedo sumergirme en la experiencia de otra persona sin sentirme sin hogar? Quizás un período preparatorio instalado con seguridad dentro de mi propia subjetividad podría darme la fuerza para pasar algún tiempo "sintiendo" a Ícaro. Pero esto me devuelve a la cuestión de mi responsabilidad para con el otro. ¿Tengo alguna vez (aunque sea temporalmente) el derecho a permitirme la ilusión de un yo separado del sufrimiento de los demás? En una versión del seder de la Pascua, el "niño malvado" pregunta qué tienen que ver las tribulaciones del pueblo judío con él. Lo que lo vuelve malo es su necesidad (¿o es su capacidad?) de separarse de la difícil situación de su pueblo.

El desprecio por el sufrimiento de los demás ha sido el foco de innumerables textos filosóficos y religiosos, y también está recibiendo atención en otros círculos. En el volumen, "Obligación escandalosa", el profesor de filosofía Eric R. Severson (2011) declara (p.20) que "... los hábitos de la cultura y la historia nos ciegan a las formas en que reproducimos y recreamos las injusticias de nuestros antepasados". Con una prosa conmovedora, nos exhorta a enfrentar nuestra "obligación escandalosa" para con los que sufren. Aunque no hay forma de responder a todos los gritos, esa es nuestra tarea como seres humanos. Se requiere responsabilidad mutua de nosotros, a pesar de saber que "... La otra persona necesita más de lo que yo puedo dar, duele más de lo que puedo ver, ha pasado por más de lo que puedo entender y espera más de lo que puedo imaginar". "En otras palabras, nuestras limitaciones no son una defensa adecuada, cuando no satisfacemos las necesidades del otro. De manera sucinta, declara (p. 94) que "... la responsabilidad es la propiedad fundamental de la existencia humana. La ética precede, por tanto, a toda filosofía". No debemos quedar atrapados en demostrar (a los demás o a nosotros mismos) que nuestras intenciones son buenas. Cuando lo hacemos, seguimos preocupados por nosotros mismos y no por los demás. Debemos poner al otro primero. Severson cita y se basa en el trabajo del filósofo Emmanuel Levinas, a quien a menudo se cita por sus convincentes relatos de lo que nos debemos el uno al otro. Levinas forjó su expresa. Este material es para uso científico y profesional exclusivamente y puede contener información clínica sensible. Los editores no se responsabilizan de los contenidos de los autores. Dirigir las consultas sobre derechos y autorizaciones a ceir@psicoterapiarelacional.es 
pensamiento a partir de la lectura de otros filósofos y de sus propias experiencias, incluidos cinco años de prisión en campos de concentración durante la Segunda Guerra Mundial.

Aunque crecí a raíz de esa guerra, la filosofía que absorbí contrastaba con esta. En la universidad y después, mis "héroes" fueron Erich Fromm, Frieda Fromm-Reichmann y Harry Stack Sullivan, entre otros, quienes predicaron una orientación muy diferente para la responsabilidad humana, que privilegia la autorrealización, aunque ciertamente no a expensas del cuidado de los demás. De hecho, para Fromm, el amor a sí mismo de la persona sana, en evolución y biofílica crece junto con el amor por los demás y el amor por todas las formas de vida. Según tengo entendido, según Fromm, nos preocupamos por nosotros mismos y por el otro porque reverenciamos la vida. Para Fromm, el amor propio es muy diferente del interés propio y el egoísmo. El destacado erudito de Fromm, Rainer Funk (que fue el último asistente de investigación de Fromm y ha escrito muchos libros y artículos extremadamente reflexivos sobre Fromm), cita (2019, p. 111) de El Arte de Amar (Fromm, 1956, p.60) diciendo que la persona egoísta se ama a sí misma muy poco, no demasiado. Básicamente, Fromm cree que, si el otro es un extraño para mí, yo soy un extraño para mí. Conocerme a mí mismo por completo es saber que la humanidad que comparto con los demás es lo más importante de mí y puede llevarme a la compasión. Entonces no me inclinaré a juzgar al otro sino, más bien, a comprender.

Esto me parece similar a la famosa máxima de Harry Stack Sullivan de que todos somos más simplemente humanos que de otra manera. Sullivan estaba enfatizando que el paciente esquizofrénico es un ser humano, con similitudes significativas con cualquier otro $y$, por lo tanto, potencialmente cognoscible. Pero la orientación humanista de su pensamiento es similar a la de Fromm en espíritu. Frieda Fromm-Reichmann también vivió estos preceptos, en su trabajo clínico y en sus relaciones con sus mentores (Hornstein, 2000).

Si bien Sontag, Levinas, Severson, Fromm, Sullivan y Fromm-Reichmann nos señalan que debemos ayudar a los demás, creo que hay una diferencia importante en el corazón de sus teorías. Los tres primeros cuentan con que hagamos lo correcto, porque reconocemos nuestra responsabilidad hacia el otro. Fromm, Sullivan y Fromm-Reichmann cuentan con que nos veamos en el otro. En mi forma de pensar, están más cerca del "sentir" de Rilke. Cuando me vea en la cara de la víctima, cuando borre la línea entre el yo y el otro, cuando el llanto de la tía de Elizabeth Bishop esté en mi propia garganta, extenderé la mano. Hasta que yo (como Rilke) no pueda soportarlo más, y entonces encontraré defensas para distanciarme. Al menos así lo he experimentado yo mismo.

Pagué mis estudios de postgrado trabajando en Hospitales de Veteranos de guerra. Con la guerra de Vietnam llegaron jóvenes mutilados, de casi mi edad, que compartían las salas con expresa. Este material es para uso científico y profesional exclusivamente y puede contener información clínica sensible. Los editores no se responsabilizan de los contenidos de los autores. Dirigir las consultas sobre derechos y autorizaciones a ceir@psicoterapiarelacional.es 
los veteranos mayores, incluidos algunos que habían visto acción en cada una de las guerras mundiales. Los contrastes fueron sorprendentes. Muchos de los veteranos de Vietnam estaban llenos de rabia y no estaban acostumbrados a sus cuerpos truncados. La mayoría de los hombres mayores estaban sometidos, algunos sonámbulos casi en coma.

Me asignaron a la sala de "hemipléjicos / parapléjicos", más conocida como la unidad de "casos en cestas", es decir, hombres que habían perdido la mayor parte o la totalidad de sus extremidades. Estaba horrorizada. Confié en esfuerzos cuidadosos para desviar mi mirada de los lugares donde deberían haber estado los brazos y las piernas. Durante los primeros días, esto pareció protegerme lo suficiente como para soportar estar allí. Sólo lo suficiente. Luego conocí a un hombre sin miembros que estaba tratando de aprender a pintar "sosteniendo" el pincel entre los dientes. Fue esto lo que me envió a la oficina del jefe para solicitar un cambio de asignación. Fue la única vez que dejé un trabajo. No pude soportarlo.

Pero, me pregunto 50 años después, ¿por qué fue esta la vista que me puso al límite? Potencialmente, este hombre valiente e ingenioso podría haber sido un espectáculo alentador, con su valiente determinación de encontrar una manera de hacer frente a su cuerpo mutilado. Sin embargo, verlo es lo que me rompió.

Mi self profesional puede fabricar una teoría para explicarlo, pero realmente no tengo ni idea de si es correcta. Debo haberme identificado más con él, y no pude soportar mirar a alguien enfrentando tan feroces probabilidades. Podía imaginarme a mí mismo dentro de él, más que nadie en la sala. "Empaparme" fue simplemente demasiado para mí. Era una especie de imagen exagerada de un extremo de mi propia determinación. Todo lo que podía ver, cuando lo miraba, era lo que costaba cada pincelada. $O$, al menos, eso es lo que fantaseo ahora. Mirarlo fue más difícil para mí que mirar a los hombres pasivos y casi sin vida que sucumbieron. Más difícil que mirar a los ancianos que habían sucumbido décadas atrás. El dolor y el terror eran más de lo que mis defensas podían contener. Recuerdo la idea simple pero valiosa que extraje de los escritos de Anna Freud (1936). La escuché decir que para entender a alguien tenemos que mirar el equilibrio entre la fuerza de sus defensas y la magnitud de lo que tienen que defender. Mirar a este paciente era como mirarse en el tipo de espejo que exagera sus rasgos, haciéndolos grotescos. Inclinó la balanza, sobrepasó mis defensas y tuve que apartar la mirada.

Aproximadamente seis años después, enfrenté otra situación desafiante, pero esta vez simplemente pude hacerle frente. Como parte de mis responsabilidades, pasaba consulta en un "hospital" en una zona rural donde el incesto era común, resultando en algunas anomalías genéticas que serían raras en una población más típica. Pero llamarlo hospital glorifica lo que en realidad era más bien un almacén donde se almacenaban los cuerpos de bebés con 
horrendas malformaciones genéticas, convenientemente lejos de la vista de sus padres. Mi tarea era ayudar a las enfermeras de la sala donde se guardaban los bebés hidrocefálicos. Estos bebés, que generalmente vivían solo semanas, tenían cabezas que cubrían gran parte de la circunferencia de sus camas. Su respuesta intelectual "más alta" fue un parpadeo. No se me escapó la ironía de que me asignaran para ayudar a estas enfermeras veteranas a sobrellevar la situación. Yo apenas podía caminar hacia la sala, y ellas sobrevivían a turnos de 8 horas. Sin embargo, como de costumbre, encontré una manera de "pasar" por competente. Me concentré en las enfermeras y ocupé mi mente imaginando qué les permitía a algunas sobrevivir mejor que a otras. En otras palabras, usé mi mente para distraerme de mi corazón. Apenas miré a los bebés todo el tiempo que estuve allí. A nivel consciente, al menos, no creo que fuera porque me identificara con ellos (como lo hice con el hombre que pintaba con los dientes). En esta situación, lo que sentí estaba más cerca del disgusto que del dolor o la compasión. No sé por qué sentí algo así como disgusto, pero recuerdo ver los cuerpecitos retorciéndose de estos bebés coronados con cabezas enormes como algo indeciblemente inquietante. Pienso ahora en las figuras de un cuadro de El Bosco, en particular en las criaturas en forma de huevo con extremidades diminutas que sobresalen. Pero estos eran bebés reales, vivos y gritando. En lo que pienso ahora es en que, al menos para mí, estaban a caballo entre lo humano y lo inanimado, entre persona y cosa y, quizás, entre vivo y muerto. Me llevaron al reino de los muertos vivientes, el lugar donde prosperan Halloween y las historias de terror. No podía mirar, pero, esta vez, mis defensas eran lo suficientemente fuertes como para permanecer en el trabajo. No creo que aparté la mirada por lástima o compasión tanto como por ansiedad. Estos bebés desafiaron una línea que necesitaba dar por sentada, por lo que no podía mirarlos con mis ojos o con el ojo de la mente. Ahora me pregunto qué defensas me permitieron cerrarles el corazón.

Edward Hirsch (1999, Como leer un poema y enamorarse de la poesía, NY, Harcourt, págs. 3236) subraya las defensas que pueden protegernos del dolor en otro poema de Bishop, "Un arte". En este poema, Bishop nos aconseja

Pierde algo todos los días. Acepta el aleteo

de llaves de puerta perdidas, la hora mal gastada.

El arte de perder no es difícil de dominar.

Bishop continúa mencionando pérdidas mayores, ciudades perdidas, hogares, posesiones preciosas. A medida que las pérdidas se multiplican y se vuelven más dolorosas, Bishop insiste en que no son desastrosas. En palabras de Hirsch (p. 30), "... me parece que las pérdidas son la expresa. Este material es para uso científico y profesional exclusivamente y puede contener información clínica sensible. Los editores no se responsabilizan de los contenidos de los autores. Dirigir las consultas sobre derechos y autorizaciones a ceir@psicoterapiarelacional.es 
verdad emocional de este poema, de la que el intelecto, a través de sus diversos giros, lucha en vano por escapar".

El final del poema deja en claro de qué se trata la batalla interior.

--- Incluso perderte (la voz en broma, un gesto

que me encanta) No habría mentido. Es evidente

el arte de perder no es muy difícil de dominar

aunque puede parecer (¡Escríbelo!) como un desastre.

Hirsch sugiere (p. 36) que el poema representa el proceso de llegar a un acuerdo con la pérdida universal. Si bien la lengua de Bishop puede estar plantada en su mejilla, y seguramente abunda la ironía, hay algo muy conmovedor (al menos para mí) en la batalla transparente y perdida de Bishop contra el dolor "maestro". El esfuerzo defensivo hace que el colapso final sea mucho más conmovedor. Me veo en su fracaso para defenderse, tanto como me veo en su dolor. Quizás esto se deba a que ese decidido "frente valiente" me resulta muy familiar.

En este poema, el dolor de Bishop es por ella misma y no (como en "La sala de espera") un yo fusionado con un otro que sufre. Pero creo que ella nos invita a sentir el deseo / la necesidad / la pérdida / el duelo en última instancia desnudos, en última instancia, la criatura inadecuadamente defendida en todos nosotros.

Cuando me diagnosticaron cáncer de mama, tuve que someterme a un tratamiento de radiación, que se complicó más por el sitio del tumor y otros factores. Antes de cada sesión de tratamiento tenía que esperar, a veces durante un período prolongado, mientras los técnicos configuraban el equipo. Esto tuvo lugar en un hospital donde los pacientes que recibieron radiación tanto para pacientes hospitalizados como ambulatorios utilizaron una sala de espera común. Nunca olvidaré la vista de una mujer, en una rueda, sujeta a múltiples tubos y bolsas de líquido. No sé cuánto de su situación estaba al tanto, pero estoy seguro de que en su rostro había una expresión de puro terror.

El extraño contraste entre la vida "normal" y ser un cuerpo atado a una camilla es exquisitamente horroroso para mí. Recuerdo una historia corta, de Alice Munro, que tiene lugar en un hogar de ancianos, donde un paciente de la sala "trasera" tenía la lengua muy agrandada, y fue referido por esa parte del cuerpo. La idea de volverme no humano (para los demás, para mí) es demasiado dolorosa para contemplarla por mucho tiempo. Mi pensamiento es que todos comenzamos la vida como recipientes, con líquidos entrando, saliendo y dando vueltas. Quizás, al menos para mí, la perspectiva más aterradora sea volver a ser una vasija. expresa. Este material es para uso científico y profesional exclusivamente y puede contener información clínica sensible. Los editores no se responsabilizan de los contenidos de los autores. Dirigir las consultas sobre derechos y autorizaciones a ceir@psicoterapiarelacional.es 
Pero mis encuentros más dolorosos con el sufrimiento fueron durante las hospitalizaciones de mi difunto esposo George. Fue atropellado por un automóvil y sufrió múltiples lesiones potencialmente mortales. La ambulancia llevó a George a un hospital de la ciudad, conocido por su sala de emergencias de primer nivel. Allí, después de una larga cirugía, lo mantuvieron en cuidados intensivos durante diez días y luego lo trasladaron a una sala donde las enfermeras con exceso de trabajo tardaban en responder, el olor medicinal era opresivo y, de alguna manera, las habitaciones lúgubres se sentían completamente anónimas y era completamente surrealista. Volví a darme "órdenes de marcha", pasando los días una hora cada vez. Me consolé con la idea de que lo peor había pasado, que, aunque estaba gravemente herido, se había recuperado bastante bien de la cirugía.

Después de un período de tiempo, el residente me explicó que querían trasladar a George a la unidad de "rehabilitación". Estaba cauteloso, preguntándome si debería presionar para que lo llevaran a un centro privado, pero el médico me convenció de que trasladarlo a otro hospital en esta etapa podría ser peligroso.

Lo primero que noté en "rehabilitación" fueron las amplias medidas de seguridad que se tomaron para que los pacientes no pudieran irse. Entrar o salir requería la ayuda de un miembro del personal y, la mayor parte del tiempo, no se los encontraba por ningún lado. Cuando entré, un nudo en el estómago me dijo el tipo de lugar que era. Los pacientes se alineaban en las paredes, cada uno en su propia silla (solo había hombres en esta sala). Me parecía que muchos habían sufrido accidentes cerebrovasculares graves. Sus cabezas colgaban, sus ojos fijos en el suelo. Algunos estaban siendo alimentados con cuchara. Si hubo algún intento de "rehabilitación", no vi señales de ello. Conseguí el alta de mi esposo lo más rápido que pude.

En esta situación, mirando los rostros de los hombres, traté de imaginar lo que podrían estar pensando y sintiendo. Lo que lo hacía tan insoportable era que no podía construir ninguna "orden de marcha" que me llevara a través del tiempo si estaba en una de esas sillas. Estaba tan agradecida de que había mucho que hacer para sacar a mi esposo. La enfermera privada que había contratado se maravilló de mi intensa concentración en la tarea que tenía entre manos. Ella no entendía que la actividad altamente enfocada estaba salvando mi vida, no solo la de mi esposo. Esta vez, la única forma en que pude resolver mis conflictos acerca de mirar a los rostros que sufrían era usar el "ver" como ímpetu para una acción determinada enérgicamente. Su sufrimiento (o lo que yo imaginaba) me fortaleció durante las horas que me llevó organizar el cuidado en casa y llevar a mi esposo a casa.

En la última hospitalización de George, él yacía entre los tubos, aturdido, dolorido, esforzándose por respirar. Y, sin embargo, las enfermeras fueron parcas al darle la morfina 
que podría haberle aliviado el dolor y la respiración. Me dijeron que tenía unos pocos días de vida como máximo. ¿Por qué esos días no podían ser lo más cómodos posible, por cualquier medio? En vano fui de un médico a otro, prácticamente pidiendo más morfina. La "política del hospital" les impidió cumplir. Indignado, le recordé a uno que su propio residente dijo que a George solo le quedaban unos días y, con la esperanza de que el médico se diera cuenta de lo absurdo de la situación, le pregunté si temían que mi esposo se volviera adicto en ese momento. El médico realmente respondió: "No creemos en la eutanasia". Estaba horrorizado por su implicación, pero me dije a mí mismo que debía mantener la calma lo suficiente para pensar qué hacer a continuación.

De vuelta en la habitación de mi esposo, me miró con ojos llenos de dolor y decepción, y suplicó, con la voz más triste que jamás haya escuchado: "¿Por qué no me ayudas?" Estoy bastante segura de que no importa cuánto tiempo pase, nunca podré sostener el recuerdo de ese momento.

Finalmente, con la ayuda de un amable trabajador social, pude llevar a George a casa para que, al menos, pudiera morir en paz. Si bien nada alivia ni cambia el dolor de esas últimas horas, a veces me encuentro repitiendo W.H. "Funeral Blues" de Auden.

Detén todos los relojes, corta el teléfono

Evita que el perro ladre con un hueso jugoso,

Silencio los pianos y con tambor amortiguado

Saca el ataúd, deja que vengan los dolientes.

Deja que los aviones giren gimiendo por encima

Garabateando en el cielo el mensaje de que ha muerto,

Pon lazos de crespón alrededor de los blancos cuellos de las palomas públicas,

Que los policías de tránsito usen guantes negros de algodón.

Él era mi norte, mi sur, mi este y mi oeste,

Mi semana laboral y mi descanso dominical,

Mi mediodía, mi medianoche, mi charla, mi canción; 
Pensé que el amor duraría para siempre: estaba equivocado.

Las estrellas no se quieren ahora: apaga todas;

Empaqueta la luna y desmonta el sol;

Derramar el océano y barrer la madera;

Porque nada ahora puede llegar a ser bueno.

\section{REFERENCIAS}

Buechler, S. (2015). Marcando la diferencia en las vidas de los pacientes. Experiencia emocional en el ámbito terapéutico. Madrid: Ágora Relacional. [V. original: Making a difference in patients' lives. New York: Routledge, 2008]

Buechler, S. (2018). Valores de la Clínica. Emociones que guían el tratamiento psicoanalítico. Madrid: Ágora Relacional [v. Original: Clinical values: Emotions that guide psychoanalytic treatment. Hillsdale, NJ: The Analytic Press, 2004]

Buechler, S. (2018). Psychoanalytic Reflections. Training and Practice. IPBooks.

Buechler, S. (2019). Comprendiendo y tratando a pacientes en psicoanálisis clínico. Lecciones desde la literatura. Madrid: Ágora Relacional. [V. original: Understanding and treating patients in Clinical Psychoanalysis. Lessons from literature. New York: Routledge, 2015]

Buechler, S. (2019). Psychoanalytic approaches to problems in living. Addressing life's changes in clinical practice. New York: Routledge.

Sontag, S. (2019). Ante el dolor de los demás. Barcelona: De bolsillo (Original de 2003).

(Se ha omitido reiterar las referencias incluidas en el propio texto)

Original recibido con fecha: 18/2/2020 Revisado: 30/9/2020 Aceptado: 30/09/2020 